\title{
Exploring health literacy in Wuhan, China: a cross-sectional analysis
}

\author{
Xin $\mathrm{Mei}^{1+}$, Qing Zhong ${ }^{1+}$, Gong Chen ${ }^{2+}$, Yuanxia Huang ${ }^{1}$ and Junlin $\mathrm{Li}^{\mathrm{i}^{*}}$
}

\begin{abstract}
Background: In recent years, research on health literacy has become increasingly focused on the health care system and public health. This cross-sectional study aimed to investigate health literacy and analyse the risk factors that affect health literacy in Wuhan, China.

Methods: Multistage stratified random sampling was used to select 5304 urban and rural residents aged 15 to 69 years from 204 monitoring points in 15 districts of Wuhan. Using the Chinese Citizen Health Literacy Questionnaire (HLQ) (2018 edition), a face-to-face survey was conducted from November to December 2018. Risk factors that may affect health literacy were assessed using the Chi-square test and multivariate logistic regression models.

Results: The knowledge rate of health literacy was relatively low (19.3\%). The knowledge rate of health-related behaviour and lifestyle (BAL, 17.3\%) was the lowest of the three aspects of health literacy, and the knowledge rate of chronic diseases (CD, 19.0\%) was the lowest of the six dimensions of health literacy. Respondents who lived in urban areas, had higher education levels, worked as medical staff, had a higher household income and did not suffer from chronic diseases were likely to have higher health literacy.
\end{abstract}

Conclusions: The health literacy levels of citizens in Wuhan are insufficient and need to improve.

\section{Background}

Health literacy [1-3] is often defined as the ability to obtain, process, and understand basic health information and services to make appropriate health decisions. As a variable associated with health outcomes, health literacy is an important component of people's health behaviours, health quality, and access to health information and health care [4]. Lower health literacy leads to obstacles in communication between health-care professionals and patients, obstruction of citizens' access to health information and inefficiency in self-health management [5-7]. Therefore, health literacy should be an important priority for the government and researchers [8]. Because of the critical

\footnotetext{
* Correspondence: lijl@whcdc.org

${ }^{+}$Xin Mei, Qing Zhong and Gong Chen are co-first authors.

'Department of Health Education, Wuhan Center for Disease Control and Prevention, No. 288 Machang Road, Changqing Street, Jianghan District, Wuhan 430024, Hubei, China

Full list of author information is available at the end of the article
}

role of health literacy in health quality, many countries, such as the United States, Canada and Australia, have treated it as a national health indicator [9-12].

In January 2008, the Chinese Ministry of Health finalized the bulletin "Chinese Resident Health LiteracyBasic Knowledge and Skills (Trial)" [13, 14], which was the first government document to define citizens' health literacy and played a vital role in the development and promotion of health education in China [15]. According to the bulletin, a Delphi process was conducted among relevant experts to choose indexes for the Chinese Citizen Health Literacy Questionnaire (HLQ) to be administered to Chinese residents [16]. After the HLQ was determined to display strong construct validity, reliability, and high acceptability [17], the national health literacy survey was conducted in 2012 and 2016. Health literacy knowledge rates, which are used to measure the level of health literacy, refer to the proportion of people with good knowledge of health literacy in the total 
population. The results indicated that the health literacy knowledge rates in 2012 and 2016 were 8.80 and $11.58 \%$ [18, 19], respectively. Widespread surveys of health literacy have been conducted in China, and the overall level of health literacy is low and a large difference in the levels of health literacy of rural and urban residents.

Health literacy is an important determinant of health. It is a comprehensive reflection of economic and social development and is influenced by various factors, such as politics, economics, culture, education and the health development level [20]. With the acceleration of urbanization in China, areas of central China around Wuhan will become the most rapidly developing district in the future. Wuhan, the capital of Hubei Province and a core city in central China, is an important industrial base, science and education centre and comprehensive transportation hub, placing it at the "heart" of Chinese economic geography [21]. With the rapid development of the economy, people's living conditions have improved substantially, and interest in health is growing. Therefore, studies investigating health literacy have important practical value. The objectives of this study are to 1) investigate the health literacy level of citizens in Wuhan, China and 2) analyse the risk factors that may affect health literacy.

\section{Methods}

\section{Participants}

In all, 5304 citizens aged 15 to 69 years who had lived in the sampled regions for more than 6 of the previous 12 months were selected in Wuhan, and 5205 were interviewed from November to December 2018 in this crosssectional survey. Participants were excluded from the survey if they refused to participate or were unable to communicate. The questionnaire was self-administered. However, if participants were unable to complete the questionnaire due to impaired vision, a poor understanding, a lower education level or other similar reasons, an interview was conducted as an alternative. In this case, the investigators would complete the questions in a neutral manner on behalf of the participants. An incentive was provided to encourage them to participate in the survey, and participants were sent small gifts (20 packages of toilet paper) as a reward for participating. The response rate of the questionnaire was $98.1 \%$. A multistage stratified random sampling method [22] was used to recruit participants. The sampling method was divided into three stages. First, residential committee villages or administrative villages were regarded as primary sampling units (PSUs), and 204 monitoring points (residential committee villages or administrative villages) were selected from the whole city using the probabilityproportional-to-size sampling (PPS) method. Then, 26 households were randomly selected from each chosen monitoring point. Finally, one eligible resident from each household was selected randomly using a Kish selection table [23]. This study was approved by the Ethics Committee of Wuhan Centre for Disease Control and Prevention, China. Written informed consent was obtained from all participants.

\section{Questionnaire}

Data were obtained in face-to-face interviews with the HLQ (2018 edition) [16] developed by the Chinese Ministry of Health. As Chinese is the common and official language of China, the questionnaire was prepared in simplified Chinese. The questionnaire consisted of three parts: (1) family support questionnaire, (2) basic personal situation, and (3) health literacy content. Based on the "Chinese Resident Health Literacy-Basic Knowledge and Skills (Trial)" and existing public health issues in China, the health literacy section (50 questions) was further categorized into three aspects and six dimensions. The three aspects were (1) knowledge and attitudes (KAA, 22 questions), (2) health-related behaviour and lifestyle (BAL, 16 questions), and (3) health-related skills (HRS, 12 questions). The six dimensions were (1) scientific views of health (SVH, 8 questions), (2) infectious diseases (ID, 6 questions), (3) chronic diseases (CD, 9 questions), (4) safety and first aid (SAFA, 10 questions), (5) medical care (MC, 11 questions), and (6) health information (HI, 6 questions). An overall health literacy score was computed as the sum of all three aspects and six dimensions.

\section{Evaluation method}

Four types of questions were included in the scale: trueor-false questions, single-answer questions, multipleanswer questions, and situation questions. For true-orfalse questions and single-answer questions, 1 point was assigned to the correct answer. For multiple-answer questions, 2 points were assigned when all of the correct answers and no incorrect answers were chosen. For situation questions, the participants were required to answer single- or multiple-answer questions after reading the given material. A score of 0 points was recorded for a wrong answer. The overall health literacy score ranged from 0 to 66 points. The total points scored in the three aspects KAA, BAL, and HRS were 28, 22 and 16, respectively, and the total points scored in the six dimensions $\mathrm{SVH}, \mathrm{ID}, \mathrm{CD}$, SAFA, MC, and HI were $11,7,12$, 14,14 , and 8 , respectively.

\section{Variables}

The participants were divided into 2 categories: (1) poor knowledge of health literacy (total health literacy score $<$ $80 \%$ of the overall score, with a total score $<53$ points) 
and (2) good knowledge of health literacy (total health literacy score $\geq 80 \%$ of the overall score, with a total score $\geq 53$ points) $[4,24]$. The knowledge rate (\%) of health literacy was calculated using the following formula: total number of participants with good knowledge of health literacy / total number surveyed $\times 100 \%$. The knowledge rates of the three aspects and six dimensions of health literacy were calculated similarly. Quality control was applied to the whole investigative process. Based on previous studies [25-30] and our results from the Chi-square test, the possible risk factors that may affect health literacy were chosen. The possible risk factors considered were the area of residence $(0=$ rural and $1=$ urban), age in years $(1=15-24,2=25-34,3=35-44$, $4=45-54,5=55-64$, and $6=65-69)$, education $(1=$ illiterate, 2 = primary school, $3=$ junior school, $4=$ high school, $5=$ college, and $6=$ master's degree or higher), occupation ( 1 = civil servant, 2 =teacher, $3=$ medical staff, $4=$ staff at other public institutions, $5=$ student, 6 = farmer, 7 = worker, $8=$ staff of other enterprises, and $9=$ other), number of people in the household $(1=1-3$, $2=4-6$, and $3=\geq 7$ ), average annual household income (CNY) $(1=<30,000,2=30,000-50,000,3=50,000-100$, $000,4=100,000-300,000$, and $5=\geq 300,000)$, suffering from chronic diseases $(0=$ no and $1=$ yes $)$, and selfreported health status $(1=$ excellent, $2=$ good, $3=$ average, $4=$ relatively poor, and 5 = poor).

\section{Statistical analysis}

The data were meticulously sorted, cleaned, and analysed with SPSS version 21 (International Business Machines Corporation, Armonk, NY, USA). A descriptive analysis (frequencies, percentages, and means with standard deviations) of participant characteristics was performed. The Chi-square test was used to compare the knowledge rates of health literacy among subgroups. A multivariate logistic regression analysis was conducted to assess the associations of multiple potential risk factors with the knowledge rate of health literacy. The multivariate logistic regression analysis was used to adjust for the risk factors associated with health literacy. Statistical significance was defined as a $p$-value $<0.05$ (two-sided).

\section{Results}

\section{Sociodemographic characteristics of the participants}

As shown in Table 1, 2408 of the participants (46.3\%) were male and 2797 (53.7\%) were female. More than half of the participants (63.7\%) lived in urban areas. The average age was $49.1 \pm 13.7$ years. Most participants were educated at the junior high school, high school or college level, accounting for $84.0 \%$ of participants. Approximately $13.4 \%$ of the participants were farmers, and the percentage of participants with
1-3 people in the household was $71.0 \%$. More than $60 \%$ of the participants had an average annual income of no more than $100,000 \mathrm{CNY}$. Of the participants, $50.1 \%$ had chronic diseases, and over $60 \%$ reported that they were in excellent or good health.

\section{The association between the knowledge rate of health literacy and the sociodemographic characteristics}

As indicated in Table 1, there were significant differences in the knowledge rates of health literacy among by area of residence, age, education, occupation, number of people in the household, household income, chronic diseases and health status $(p<0.05)$ but not by gender, ethnicity and native population.

\section{Average score, knowledge rate of total health literacy and the three aspects and six dimensions of health literacy}

The average scores for each health literacy scale are shown in Table 2. The knowledge rates of the three aspects KAA, HRS, and BAL were 33.9, 33.2 and 17.3\%, respectively. Additionally, for the six dimensions, the knowledge rate in descending order was 57.8, 52.8, 41.0, 27.8, 26.1, and $19.0 \%$ for SAFA, SVH, HI, MC, ID, and $\mathrm{CD}$, respectively.

\section{Multivariate logistic regression analysis of risk factors associated with the health literacy knowledge rate}

The variables with statistical significance in the Chisquare test (Table 1) were examined in the multivariate logistic regression analysis. As shown in Table 3, participants living in urban areas $(\mathrm{OR}=1.31,95 \% \mathrm{CI}$ : 1.08 , 1.60) were significantly likely to have a higher knowledge rate of health literacy than participants living in rural areas. Compared to participants who were illiterate, participants with an education level of high school $(\mathrm{OR}=$ 2.27, 95\% CI: 1.00, 5.13), college (OR $=5.36$, 95\% CI: $2.35,12.23)$ and master's degree or higher $(\mathrm{OR}=6.67$, $95 \%$ CI: $2.70,16.46)$ were likely to have a significantly higher health literacy knowledge rate. Medical staff $(\mathrm{OR}=2.42,95 \% \mathrm{CI}: 1.36,4.32)$ were likely to have higher health literacy levels than residents whose occupation was a civil servant. As the average household income increased, the participants were more likely to present higher health literacy levels. Participants suffering from chronic disease were more likely to present lower health literacy levels. Of these factors, living in an urban area, education level (except primary school and junior school), working as medical staff and having a higher annual household income were positively correlated with health literacy, while being a worker or suffering from chronic diseases were negatively correlated with health literacy. 
Table 1 Sociodemographic characteristics and knowledge rate of health literacy in Wuhan in 2018

\begin{tabular}{|c|c|c|c|c|c|}
\hline Characteristics & $\mathrm{N}(\%)^{a}$ & $>80 \%$ score $^{b}$ & Knowledge rate (\%) & $x^{2}$ & $P$ \\
\hline \multicolumn{6}{|l|}{ Area of residence } \\
\hline Urban & 3315 (63.7) & 773 & 23.3 & \multirow[t]{2}{*}{95.20} & \multirow[t]{2}{*}{$<0.001$} \\
\hline Rural & $1890(36.3)$ & 231 & 12.2 & & \\
\hline \multicolumn{6}{|l|}{ Gender } \\
\hline Male & $2408(46.3)$ & 450 & 18.7 & \multirow[t]{2}{*}{1.04} & \multirow[t]{2}{*}{0.308} \\
\hline Female & $2797(53.7)$ & 554 & 19.8 & & \\
\hline \multicolumn{6}{|l|}{ Age, years } \\
\hline $15-24$ & $209(4.0)$ & 65 & 31.1 & \multirow[t]{6}{*}{210.58} & \multirow[t]{6}{*}{$<0.001$} \\
\hline $25-34$ & 759 (14.6) & 212 & 27.9 & & \\
\hline $35-44$ & $853(16.4)$ & 261 & 30.6 & & \\
\hline $45-54$ & $1232(23.7)$ & 218 & 17.7 & & \\
\hline $55-64$ & $1343(25.8)$ & 154 & 11.5 & & \\
\hline $65-69$ & $809(15.5)$ & 94 & 11.6 & & \\
\hline \multicolumn{6}{|l|}{ Ethnicity } \\
\hline Han & 5168 (99.3) & 993 & 19.2 & \multirow[t]{2}{*}{2.61} & \multirow[t]{2}{*}{0.106} \\
\hline Other & $37(0.7)$ & 11 & 29.7 & & \\
\hline \multicolumn{6}{|l|}{ Education } \\
\hline Illiterate & $141(2.7)$ & 7 & 5.0 & \multirow[t]{6}{*}{768.04} & \multirow[t]{6}{*}{$<0.001$} \\
\hline Primary school & $550(10.6)$ & 30 & 5.5 & & \\
\hline Junior school & $1431(27.5)$ & 87 & 6.1 & & \\
\hline High school & $1524(29.3)$ & 235 & 15.4 & & \\
\hline College & $1417(27.2)$ & 567 & 40.0 & & \\
\hline Master's degree or higher & $142(2.7)$ & 78 & 54.9 & & \\
\hline \multicolumn{6}{|l|}{ Occupation } \\
\hline Civil servant & $89(1.7)$ & 39 & 43.8 & \multirow[t]{9}{*}{677.64} & \multirow[t]{9}{*}{$<0.001$} \\
\hline Teacher & $231(4.4)$ & 130 & 56.3 & & \\
\hline Medical staff & $127(2.4)$ & 71 & 55.9 & & \\
\hline Staff at other public institutions & $608(11.7)$ & 228 & 37.5 & & \\
\hline Student & $110(2.1)$ & 43 & 39.1 & & \\
\hline Farmer & $699(13.4)$ & 41 & 5.9 & & \\
\hline Worker & $684(13.1)$ & 56 & 8.2 & & \\
\hline Staff of other enterprises & $815(15.7)$ & 144 & 17.7 & & \\
\hline Other & $1842(35.4)$ & 252 & 13.7 & & \\
\hline \multicolumn{6}{|l|}{ Number of people in the household } \\
\hline $1-3$ & $3695(71.0)$ & 680 & 18.4 & \multirow[t]{3}{*}{6.450} & \multirow[t]{3}{*}{0.040} \\
\hline $4-6$ & $1447(27.8)$ & 310 & 21.4 & & \\
\hline$\geq 7$ & $63(1.2)$ & 14 & 22.2 & & \\
\hline \multicolumn{6}{|c|}{ Average annual household income, CNY } \\
\hline$<30,000$ & $539(10.4)$ & 21 & 3.9 & \multirow[t]{5}{*}{268.12} & \multirow[t]{5}{*}{$<0.001$} \\
\hline $30,000-50,000$ & $969(18.6)$ & 87 & 9.0 & & \\
\hline $50,000-100,000$ & $1826(35.1)$ & 367 & 20.1 & & \\
\hline $100,000-300,000$ & $1589(30.5)$ & 478 & 30.1 & & \\
\hline$\geq 300,000$ & $282(5.4)$ & 51 & 18.1 & & \\
\hline
\end{tabular}

Native population 
Table 1 Sociodemographic characteristics and knowledge rate of health literacy in Wuhan in 2018 (Continued)

\begin{tabular}{|c|c|c|c|c|c|}
\hline Characteristics & $\mathrm{N}(\%)^{\mathrm{a}}$ & $>80 \%$ score $^{b}$ & Knowledge rate (\%) & $x^{2}$ & $P$ \\
\hline Yes & $4648(89.3)$ & 894 & 19.2 & 0.09 & 0.771 \\
\hline No & $557(10.7)$ & 110 & 19.7 & & \\
\hline \multicolumn{6}{|c|}{ Suffering from chronic diseases ${ }^{c}$} \\
\hline Yes & $2610(50.1)$ & 370 & 14.2 & 87.91 & $<0.001$ \\
\hline No & $2595(49.9)$ & 634 & 24.4 & & \\
\hline \multicolumn{6}{|c|}{ Self-reported health status } \\
\hline Excellent & $1138(21.9)$ & 238 & 20.9 & 9.66 & 0.047 \\
\hline Good & $2203(42.3)$ & 444 & 20.2 & & \\
\hline Average & $1643(31.6)$ & 288 & 17.5 & & \\
\hline Relatively poor & $186(3.6)$ & 31 & 16.7 & & \\
\hline Poor & $35(0.7)$ & 3 & 8.6 & & \\
\hline Total & $5205(100.0)$ & 1004 & 19.3 & - & - \\
\hline
\end{tabular}

apercentage of all participants; ${ }^{b}$ number of participants with a total score greater than $80 \% ;{ }^{c}$ chronic diseases included hypertension, heart disease, cerebrovascular disease (stroke, cerebral infarction, cerebral thrombosis), diabetes, and malignant cancer

\section{Discussion}

The analysis of the risk factors may not only help identify key groups and areas where health literacy is limited but also indicate targeted intervention measures. With the development of the economy, we should strengthen quality-oriented education, popularize health-related knowledge and skills, and strive to improve people's health literacy levels. In our study conducted in Wuhan, China, the knowledge rate of health literacy was $19.3 \%$ (with an average score of $42.9 \pm 11.7$ ), which was a little higher than the average level of Chinese residents in 2018 (17.1\%) [31], but still constituted a large gap compared with the knowledge rate in developed areas [17] (32.3\% in Beijing, China). The high proportions of people with a limited knowledge rate of health literacy indicate that the health literacy deficit is a challenge for researchers, community organizations, health care providers, and policy-makers [17].

In terms of the three aspects, the knowledge rate of health literacy related to BAL (17.3\%) was comparatively lower than the other two components of comprehensive health literacy: KAA (33.9\%) and HRS (33.2\%). Based on this finding, Chinese people may lack awareness that a healthy lifestyle can help prevent diseases rather than only cure them. Because China is a developing country, this lack of awareness may be associated with socio-cultural and economic limitations. In addition, based on the theory of knowledge, attitude and practice (KAP), changes in healthrelated behaviour are divided into three continuous processes: obtaining knowledge, forming faith and

Table 2 Average score and knowledge rate of each scale in the three aspects and six dimensions

\begin{tabular}{|c|c|c|c|c|c|c|}
\hline Variables $^{a}$ & Number of questions & Total points & $80 \%$ of the total score & Mean \pm SD & $>80 \%$ score $^{b}$ & Knowledge rate (\%) \\
\hline \multicolumn{7}{|l|}{ Three aspects } \\
\hline KAA & 22 & 28 & 22.4 & $19.1 \pm 5.0$ & 1767 & 33.9 \\
\hline BAL & 16 & 22 & 17.6 & $13.3 \pm 4.5$ & 900 & 17.3 \\
\hline HRS & 12 & 16 & 12.8 & $10.5 \pm 3.6$ & 1728 & 33.2 \\
\hline \multicolumn{7}{|l|}{ Six dimensions } \\
\hline $\mathrm{SVH}$ & 8 & 11 & 8.8 & $7.4 \pm 2.5$ & 2749 & 52.8 \\
\hline ID & 6 & 7 & 5.6 & $4.6 \pm 1.5$ & 1356 & 26.1 \\
\hline$C D$ & 9 & 12 & 9.6 & $7.0 \pm 2.7$ & 988 & 19.0 \\
\hline SAFA & 10 & 14 & 11.2 & $10.5 \pm 3.0$ & 3008 & 57.8 \\
\hline$M C$ & 11 & 14 & 11.2 & $8.7 \pm 2.8$ & 1449 & 27.8 \\
\hline $\mathrm{HI}$ & 6 & 8 & 6.4 & $4.8 \pm 2.1$ & 2132 & 41.0 \\
\hline Health literacy & 50 & 66 & 52.8 & $42.9 \pm 11.7$ & 1004 & 19.3 \\
\hline
\end{tabular}

${ }^{a} K A A$ Knowledge and attitudes, BAL Health-related behaviour and lifestyle, HRS Health-related skills, SVH Scientific views of health, ID Infectious diseases, CD Chronic diseases, SAFA Safety and first aid, MC Medical care, HI Health information. ${ }^{\mathrm{b}}$ Number of participants with a total score $>80 \%$ 
Table 3 Multivariate logistic regression analysis of risk factors associated with health literacy in participants stratified by different socio-demographic characteristics

\begin{tabular}{|c|c|c|c|c|c|c|c|}
\hline Parameters & B & S.E. & Wald & df & $\mathbf{P}$ & OR & OR $95 \% \mathrm{Cl}$ \\
\hline \multicolumn{8}{|l|}{ Residence } \\
\hline Rural & ref & & & & & & \\
\hline Urban & 0.27 & 0.10 & 7.26 & 1 & 0.01 & 1.31 & $(1.08,1.60)$ \\
\hline \multicolumn{8}{|l|}{ Age, years old } \\
\hline $15-24$ & ref & & & & & & \\
\hline $25-34$ & 0.06 & 0.24 & 0.07 & 1 & 0.79 & 1.07 & $(0.67,1.70)$ \\
\hline $35-44$ & 0.29 & 0.24 & 1.46 & 1 & 0.23 & 1.34 & $(0.83,2.14)$ \\
\hline $45-54$ & 0.01 & 0.24 & 0.00 & 1 & 0.96 & 1.01 & $(0.63,1.63)$ \\
\hline $55-64$ & -0.37 & 0.25 & 2.29 & 1 & 0.13 & 0.69 & $(0.42,1.12)$ \\
\hline $65-69$ & -0.01 & 0.26 & 0.00 & 1 & 0.96 & 0.99 & $(0.59,1.66)$ \\
\hline \multicolumn{8}{|l|}{ Education } \\
\hline Illiterate & ref & & & & & & \\
\hline Primary school & 0.02 & 0.44 & 0.00 & 1 & 0.96 & 1.02 & $(0.43,2.41)$ \\
\hline Junior school & 0.03 & 0.42 & 0.00 & 1 & 0.95 & 1.03 & $(0.45,2.32)$ \\
\hline High school & 0.82 & 0.42 & 3.88 & 1 & $<0.05$ & 2.27 & $(1.00,5.13)$ \\
\hline College & 1.68 & 0.42 & 15.97 & 1 & $<0.01$ & 5.36 & $(2.35,12.23$ \\
\hline Master's degree or higher & 1.90 & 0.46 & 16.91 & 1 & $<0.01$ & 6.67 & $(2.70,16.46)$ \\
\hline
\end{tabular}

Occupation

Civil servant $\quad$ ref

Medical staff

$0.60 \quad 0.26$

\subsection{9}

0.02

1.83

$(1.09,3.07)$

Staff at other public institutions

0.88

0.29

9.02

$<0.01$

2.42

$(1.36,4.32)$

0.12

0.24

0.62

$(0.70,1.81)$

Student

0.31

0.24

0.72

0.40

1.13

$(0.67,2.80)$

Farmer

$-0.28$

0.31

1.37

$(0.41,1.38)$

Worker

$-0.79$

0.36

0.75

$(0.27,0.78)$

Staff of other enterprises

0.28

$<0.01$

0.46

$(0.30,0.79)$

Other

$-0.72$

0.25

$<0.01$

0.49

$(0.40,1.02)$

Number of people in the household

$1-3$

ref

4-6

$-0.04$

0.24

0.06

0.64

$\geq 7$

0.37

0.09

0.19

0.67

0.96

$(0.81,1.15)$

Average household income per month (CNY)

$$
\begin{aligned}
& <30,000 \\
& 30,000-50,000 \\
& 50,000-100,000 \\
& 100,000-300,000 \\
& \geq 300,000
\end{aligned}
$$

ref

0.51

1.21

0.35

1.11

0.29

1.44

$(0.73,2.86)$

1.41

0.65

\subsection{6}

3.92

0.24

25.81

0.24

0.29

5.06

ref

No
Yes

$-0.18$

0.09

4.41

0.04

0.83

$(0.70,0.99)$

Self-reported health status

Excellent

ref

Good

0.05

0.10

0.26

0.61

1.05

$(0.86,1.29)$

$(2.11,5.37)$

$(2.57,6.57)$

$(1.09,3.35)$$$
\text { (1.09, 3.35) }
$$ 
Table 3 Multivariate logistic regression analysis of risk factors associated with health literacy in participants stratified by different socio-demographic characteristics (Continued)

\begin{tabular}{llllllll}
\hline Parameters & B & S.E. & Wald & df & P & OR & OR 95\% Cl \\
\hline General & 0.05 & 0.11 & 0.17 & 1 & 0.68 & 1.05 & $(0.84,1.31)$ \\
Relatively poor & 0.20 & 0.24 & 0.66 & 1 & 0.42 & 1.22 & $(0.76,1.96)$ \\
Poor & -0.11 & 0.65 & 0.03 & 1 & 0.87 & 0.90 & $(0.25,3.23)$ \\
Constant & -3.34 & 0.58 & 33.20 & 1 & $<0.01$ & 0.04 & - \\
\hline
\end{tabular}

${ }^{a}$ Chronic diseases included hypertension, heart disease, cerebrovascular disease (stroke, cerebral infarction, cerebral thrombosis), diabetes, and malignant cancer

producing behaviour. Knowledge is comparatively easy to obtain, but the formation of faith and subsequent production of health-related behaviour takes longer, indicating that health education and promotion should focus not only on health knowledge but also on health-related behaviour. Risk factors may affect the health-related behaviour of different groups in different ways; thus, individually targeted health education and health promotion activities should be developed.

The knowledge rate of CD (19.0\%) was the lowest of the 6 dimensions, consistent with the study by Zhang Y et al. [32]. Chronic disease is the leading global health threat, and the costs of chronic disease are steep, not only for individuals but also for families and society [33]. According to the survey, $29.08 \%$ of the participants suffered from chronic diseases, and a lower health literacy knowledge rate of $C D$ was observed. Participants who were not suffering from chronic diseases had a higher knowledge rate of health literacy, consistent with the results reported by Rafferty AP et al. [34] and Beauchamp A et al. [35]. Restricted interpersonal relations, social resources and scope of activity might be related to the accessibility of health information, which may affect the level of health literacy. Inadequate health literacy poses a major barrier to educating patients with chronic diseases [35]. Meanwhile, citizens with low CD levels may have difficulty improving their lifestyles, managing their diseases, and participating in complex decisions about treatment [8]. Hence, we should strengthen health education and promote health literacy in the future, particularly in terms of CD.

In our study, the multivariate logistic regression analysis indicated that the area of residence, education level, occupation, household income and suffering from chronic diseases may affect health literacy.

A higher knowledge rate of health literacy was observed for participants who lived in urban areas than participants who lived in rural areas, consistent with the results reported by Wang W et al. [36]. Thus, a higher health literacy level was associated with an urban residence. The potential explanation is that participants living in urban areas have easy access to high-quality health information and medical information services. Therefore, rural areas are key areas for future health education and health promotion.

The education level may be one of the most important positive factors contributing to health literacy [37]. The knowledge rate of health literacy increased as the education level increased (except between primary school and junior school), consistent with the results reported by Manafo E et al. [38] and McClintock $\mathrm{H}$ et al. [39]. The same result was obtained for the factor of occupation, as medical staff have a higher level of health literacy, which might result from medical professional knowledge and a higher education level [15]. A low level of education is related to a poor reading and comprehension ability, which may cause people to make poor or indirect use of health information and media. Therefore, improving the education level of residents is fundamental to increasing health literacy. For people with a low educational level, we should apply a popular propagation mode and develop health communication materials that are easy to understand.

Higher health literacy levels have consistently been reported to be associated with higher household income [24, 26], similar to our results. The knowledge rate of health literacy was lower in participants with a lower household income level. With increasing household income, the participants likely paid more attention to selfhealth management and quality of life. According to a study by Pawlak R [40] a lower income level is an important reason for a low health literacy level, which leads to worse health and a greater rate of hospitalization. For low-income groups, an increase in the household income and improvements in the health care system are very important for improving the health level.

In our study, the health literacy of people with chronic diseases was low, consistent with the results reported by Sorensen K et al. [9] and Wu L et al. [41]. Notably, the risk of chronic diseases in elderly people also increases when they are suffering from chronic diseases. Therefore, interventions designed to help people suffering from chronic diseases stay healthy and improve the quality of life in their later years are very important [22, 42].

In conclusion, the survey extends the scientific evidence on health literacy by measuring the knowledge 
rate of health literacy in Wuhan, China. Limited health literacy and a social gradient in health literacy represent important challenges for health policies and practices in Wuhan. This health literacy deficit and inequality should be addressed by Wuhan health planners and policymakers, and appropriate public health and health promotion strategies should be developed.

This study has some limitations. All the data were analysed based on self-report measures. Therefore, the programme may be subject to bias. First, the study employed a cross-sectional design; hence, the analysis did not permit causal inferences. Second, health literacy, by definition, emphasizes health skills and applications. However, the survey of health literacy focused on knowledge, which has little involvement in skills and application. Finally, we assessed health literacy in three categories: total health literacy, three aspects of health literacy and six dimensions of health literacy. However, when designing the questionnaire, the complexity and quantity of questions in different categories should be balanced.

\section{Conclusions}

The knowledge rate of health literacy of Wuhan residents is relatively low (19.3\%). The knowledge rate of health-related behaviour and lifestyle (BAL, 17.3\%) is the lowest of the three aspects of health literacy, and the knowledge rate of chronic diseases (CD, 19.0\%) is the lowest of the six dimensions of health literacy. The knowledge rate of health literacy was negatively associated with respondents living in rural areas, with a low education level, a low household income, and suffering from chronic diseases. Thus, health education and promotion interventions should be targeted to high-priority topics (BAL and CD), key areas (rural) and high-risk populations (people who are illiterate, have a low annual income and suffer from chronic diseases) to improve health outcomes.

\section{Abbreviations}

HLQ: Chinese Citizen Health Literacy Questionnaire; KAA: Knowledge and attitudes; BAL: Health-related behaviour and lifestyle; HRS: Health-related skills; SVH: Scientific views of health; ID: Infectious diseases; CD: Chronic diseases; SAFA: Safety and first aid; MC: Medical care; HI: Health information

\section{Acknowledgements}

The authors would like to thank all the participants involved in this survey. The authors express their special thanks to the Center for Disease Prevention and Control in 15 districts in Wuhan.

\section{Authors' contributions}

Conceived and designed the study: $\lrcorner$ and $Y H$. Study implementation: $\lrcorner$ and YH. Drafted the manuscript: GC, XM and QZ. Reviewed the paper: $J \mathrm{~L}, \mathrm{YH}, \mathrm{XM}$, QZ and GC. All authors read and approved the final manuscript.

\section{Funding}

No funding was received.

\section{Availability of data and materials}

The data used and/or analysed in the current study are not publicly available because restrictions apply to the availability of these data. Data are, however, available from the corresponding author on reasonable request and with permission of the Wuhan Center for Disease Control and Prevention.

\section{Ethics approval and consent to participate}

The study protocol was approved by the Ethics Committee of the Wuhan Center for Disease Control and Prevention. Written informed consent was obtained from all participants and a parent or guardian of participants aged less than 17 years.

\section{Consent for publication}

Not applicable.

\section{Competing interests}

The authors have no competing interests to declare.

\section{Author details}

${ }^{1}$ Department of Health Education, Wuhan Center for Disease Control and Prevention, No. 288 Machang Road, Changqing Street, Jianghan District, Wuhan 430024, Hubei, China. ${ }^{2}$ Medical Department, The Central Hospital of Wuhan, Tongji Medical College, Huazhong University of Science and Technology, No. 26 Shengli Street, Jiang'an District, Wuhan 430014, Hubei, China

Received: 27 October 2019 Accepted: 8 September 2020

Published online: 17 September 2020

\section{References}

1. Nutbeam D. Health literacy as a public health goal: a challenge for contemporary health education and communication strategies in the 21st century. Health Promot Int. 2000;15(3):259-67.

2. Rowlands G, Khazaezadeh N, Oteng-Ntim E, Seed P, Barr S, et al. Development and validation of a measure of health literacy in the UK: the newest vital sign. BMC Public Health. 2013;13(1):116.

3. Smith BJ, Tang KC, Nutbeam D. WHO health promotion glossary: new terms. Health Promot Int. 2006;21(4):340-5.

4. Rong H, Cheng X, Garcia JM, Zhang L, Lu L, et al. Survey of health literacy level and related influencing factors in military college students in Chongqing, China: a cross-sectional analysis. PLoS One. 2017;12(5):e177776.

5. Sayah FA, Majumdar SR, Williams B, Robertson S, Johnson JA. Health literacy and health outcomes in diabetes: a systematic review. J Gen Intern Med. 2013;28(3):444-52.

6. Sun X, Shi Y, Zeng Q, Wang Y, Du W, et al. Determinants of health literacy and health behavior regarding infectious respiratory diseases: a pathway model. BMC Public Health. 2013;13:261.

7. Berkman N, Sheridan S, Donahue K, Halpern D, Viera A, et al. Health literacy interventions and outcomes: an updated systematic review. Evid Rep Technol Assess. 2011;199:1-941.

8. $\quad$ Lancet T. Taking health literacy seriously. Lancet. 2005;366(9480):95.

9. Sorensen K, Pelikan JM, Rothlin F, Ganahl K, Slonska Z, et al. Health literacy in Europe: comparative results of the European health literacy survey (HLSEU). Eur J Pub Health. 2015;25(6):1053-8.

10. Heijmans M, Uiters E, Rose T, Ter H, Deville W, et al. Study on sound evidence for a better understanding of health literacy in the European Union. Brussels: European Commission; 2015.

11. Rajah R, Ahmad HM, Jou LC, Murugiah MK. The perspective of healthcare providers and patients on health literacy: a systematic review of the quantitative and qualitative studies. Perspect Public Health. 2018; 138(2):122-32.

12. Rowlands G, Dodson S, Leung A, Levin-Zamir D. Global Health systems and policy development: implications for health literacy research, theory and practice. Stud Health Technol Inform. 2017;240:359-91.

13. Chinese $\mathrm{MOH}$. Chinese resident health literacy - basic knowledge and skills (trial). Chinese J Health Educ. 2009;1(25):3-4.

14. Li XH. Brief introduction on identification and dissemination of the basic knowledge and skill of People's health literacy by Chinese government. Chinese J Health Educ. 2008;24(5):385-8. 
15. Wang $X$, Guo $H$, Wang L, Li X, Huang $M$, et al. Investigation of residents' health literacy status and its risk factors in Jiangsu Province of China. Asia Pac J Public Health. 2015;27(2):2764-72.

16. Shen M, Hu M, Liu S, Chang Y, Sun Z. Assessment of the Chinese resident health literacy scale in a population-based sample in South China. BMC Public Health. 2015;15:637.

17. Wu Y, Wang L, Cai Z, Bao L, Ai P, et al. Prevalence and risk factors of low health literacy: a community-based study in Shanghai, China. Int J Environ Res Public Health. 2017;14(6):628.

18. Li L, Li YH, Nie XQ, Huang XG, Shi MF, et al. Influence factors of health literacy monitoring of Chinese residents on 2012. Chinese J Health Educ. 2015;2(31):104-7.

19. Department $P$. Results of Chinese residents health literacy in 2016 was released.; 2017.

20. Sorensen K, Van den Broucke S, Fullam J, Doyle G, Pelikan J, et al. Health literacy and public health: a systematic review and integration of definitions and models. BMC Public Health. 2012;12:80.

21. Tourism WMBO. Big river, big lake, big Wuhan; 2019.

22. Zhang $D$, Wu S, Zhang $Y$, Yang $P$, Maclntyre $C R$, et al. Health literacy in Beijing: an assessment of adults' knowledge and skills regarding communicable diseases. BMC Public Health. 2015:15:799.

23. Munyogwa MJ, Mtumwa AH. The prevalence of abdominal obesity and its correlates among the adults in Dodoma region, Tanzania: A CommunityBased Cross-Sectional Study. Adv Med. 2018;2018:6123156.

24. Zhang Y, Zhang A, Hu P, Huang W, Lu L, et al. Exploring health literacy in nursing students of Chongqing, China: a cross-sectional survey using the health literacy questionnaire. Lancet. 2016;388:599.

25. Liu Y, Wang Y, Liang F, Chen Y, Liu L, et al. The health literacy status and influencing factors of older population in Xinjiang. Iran J Public Health. 2015:44(7):913-9.

26. Liu YB, Liu L, Li YF, Chen YL. Relationship between health literacy, healthrelated behaviors and health status: a survey of elderly Chinese. Int Environ Res Public Health. 2015;12(8):9714-25.

27. Xie $Y$, Ma M, Zhang $Y$, Tan X. Factors associated with health literacy in rural areas of Central China: structural equation model. BMC Health Serv Res. 2019;19(1):300.

28. Nie X, Li Y, Li L, Huang $X$. A study on health information literacy among urban and suburban residents in six provinces in China. Chinese J Prev Med. 2014:48(7):566-70

29. Schrauben SJ, Wiebe DJ. Health literacy assessment in developing countries: a case study in Zambia. Health Promot Int. 2017;32(3):475-81.

30. Heide IV, Rademakers J, Schipper M, Droomers M, Sorensen K, et al. Health literacy of Dutch adults: a cross sectional survey. BMC Public Health. 2013;13:179.

31. Department $P$. The National Health and health Commission's regular press conference on august 27, 2019.

32. Zhang $Y$, Zhang F, Hu P, Huang W, Lu L, et al. Exploring health literacy in Medical University students of Chongqing, China: A Cross-Sectional Study. PLOS ONE. 2016;11(4):e152547.

33. Wang $C$, Kane RL, Xu D, Meng Q. Health literacy as a moderator of healthrelated quality of life responses to chronic disease among Chinese rural women. BMC Womens Health. 2015;15:34.

34. Rafferty AP, Luo H, Little N, Imai S, Winterbauer NL, et al. Self-reported health literacy among North Carolina adults and associations with health status and chronic health conditions. N C Med J. 2020;81(2):87-94.

35. Beauchamp A, Buchbinder R, Dodson S, Batterham RW, Elsworth GR, et al. Distribution of health literacy strengths and weaknesses across sociodemographic groups: a cross-sectional survey using the health literacy questionnaire (HLQ). BMC Public Health. 2015;15:678.

36. Wang $W$, Zhang $Y$, Lin B, Mei $Y$, Ping Z, et al. The urban-rural disparity in the status and risk factors of health literacy: a cross-sectional survey in Central China. Int J Environ Res Public Health. 2020;17(11):3848.

37. Lee SY, Tsai TI, Tsai YW, Kuo KN. Health literacy, health status, and healthcare utilization of Taiwanese adults: results from a national survey. BMC Public Health. 2010;10:614

38. Manafo E, Wong S. Health literacy programs for older adults: a systematic literature review. Health Educ Res. 2012;27(6):947-60.

39. McClintock H, Schrauben S, Andrews A, Wiebe D. Measurement of health literacy to advance global health research: a study based on demographic and health surveys in 14 sub-Saharan countries. Lancet Glob Health. 2017;5:S18.

40. Pawlak R. Economic considerations of health literacy. Nurs Econ. 2005:23: 173-80 147
41. Wu L, Chen $H, H u Y$, Xiang $H, Y u X$, et al. Prevalence and associated factors of elder mistreatment in a rural community in People's Republic of China: a cross-sectional study. PLoS One. 2012;7(3):e33857.

42. Baker DW, Wolf MS, Feinglass J, Thompson JA, Gazmararian JA, et al. Health literacy and mortality among elderly persons. Arch Intern Med. 2007;167(14): 1503-9.

\section{Publisher's Note}

Springer Nature remains neutral with regard to jurisdictional claims in published maps and institutional affiliations.

\section{Ready to submit your research? Choose BMC and benefit from:}

- fast, convenient online submission

- thorough peer review by experienced researchers in your field

- rapid publication on acceptance

- support for research data, including large and complex data types

- gold Open Access which fosters wider collaboration and increased citations

- maximum visibility for your research: over $100 \mathrm{M}$ website views per year

At $\mathrm{BMC}$, research is always in progress.

Learn more biomedcentral.com/submissions 